\title{
Factors associated with reductions in alcohol use between high school and college: an analysis of data from the College Alcohol Study
}

This article was published in the following Dove Press journal:

Substance Abuse and Rehabilitation

12 February 2014

Number of times this article has been viewed

\section{Christopher A Swann' \\ Michelle Sheran' \\ Diana Phelps ${ }^{2}$}

'Department of Economics, University of North Carolina at Greensboro, Greensboro, NC, USA; ${ }^{2}$ RTI International, Research Triangle Park, NC, USA
Correspondence: Christopher A Swann Department of Economics, University of North Carolina at Greensboro, 1400 Spring Garden Street Greensboro, NC 274I2, USA

Email chris_swann@uncg.edu
Background: The consumption of alcohol by college students is a significant public health concern, and a large amount of literature explores this issue. Much of the focus is on the prevalence and correlates of binge drinking. Relatively few studies explore reductions in drinking, and these generally focus on reductions that occur during college.

Aims: We examined the transition between high school and college and sought to understand the characteristics and behaviors of students that are related to reductions in the consumption of alcohol during this transition.

Methods: We used data from all four rounds of the Harvard School of Public Health's College Alcohol Survey and logistic regression models to relate the status of reduced alcohol consumption to five groups of variables: demographic and parental variables, other substance use, social environment, student activities, and alcohol policies.

Results: A number of characteristics were related to reductions in drinking. Students whose fathers did not attend college were more likely to reduce alcohol consumption (odds ratio $[\mathrm{OR}]=1.28 ; 95 \%$ confidence interval $[\mathrm{CI}]=1.06-1.55)$, whereas students who prioritize parties $(\mathrm{OR}=0.35 ; \mathrm{CI}=0.30-0.43)$ and who have recently smoked cigarettes $(\mathrm{OR}=0.52 ; \mathrm{CI}=0.41-0.64)$ or marijuana $(\mathrm{OR}=0.52 ; \mathrm{CI}=0.40-0.67)$ or whose fathers are moderate $(\mathrm{OR}=0.73 ; \mathrm{CI}=0.55-0.96)$ or heavy ( $\mathrm{OR}=0.72 ; \mathrm{CI}=0.53-0.96)$ drinkers were less likely to reduce alcohol consumption.

Conclusion: The results highlight the importance of family background and social environment on reductions in drinking.

Keywords: binge drinking, College Alcohol Study, college drinking, reductions in alcohol consumption

\section{Introduction}

High rates of alcohol consumption among college students have been shown to have significant consequences. ${ }^{1-5}$ For example, alcohol-related deaths among 18 to 24 -year-old college students in the United States are estimated to have increased from 1,442 in 1998 to 1,825 in 2005, and in 2001 almost 700,000 students were estimated to have experienced some type of assault by other students who had been drinking. ${ }^{5}$ Of particular concern is "binge drinking", defined throughout this paper as the consumption of five or more drinks by men and four or more drinks by women on one occasion. Using this definition, surveys of US college students indicate that over 40 percent are binge drinkers. ${ }^{6}$

A number of studies have looked at factors associated with increases in drinking between high school and college in the US. These studies consider, for example, the initiation of any drinking ${ }^{7}$ and the initiation of binge drinking ${ }^{8}$ between high school and freshman year of college; lifetime exposure to alcohol, tobacco, and illegal drugs and 
subsequent patterns of use before and during college; ${ }^{9}$ and increases in men's drinking behavior, including binge drinking, between high school and the first month of college. ${ }^{10}$

Despite the potential to learn about students' drinking behavior by studying students who reduce their consumption, there are relatively few studies of reductions in drinking, and most of these consider reductions that occur during college rather than during the transition to college. These include US studies of changes in alcohol consumption during college allowing for increases and decreases in consumption ${ }^{11}$ and of the cessation of binge drinking. ${ }^{12}$ Research has also explored the roles of alcohol education, social norms campaigns, alcohol counter-marketing, and alcohol control policies on US colleges and universities in reducing consumption by college students during college. ${ }^{13}$

In contrast to these studies of reductions during college, a few studies consider reductions between high school and college. ${ }^{9,14,15}$ For example, Reifman and Watson ${ }^{14}$ explored factors associated with changes in binge drinking behavior between high school and college and found that approximately 15 percent of all students were binge drinkers in high school but not in college. Of students who were binge drinkers in high school, 31 percent were categorized as not being binge drinkers in college. Their analysis found that social variables such as networks of friends and the importance of parties were significant factors in continuing versus stopping binge drinking in college.

In a similar spirit, we seek to identify the characteristics and behaviors of students that are related to reductions in alcohol consumption between senior year of high school and freshman year of college. It is important to understand this relationship because, as noted by Reifman and Watson, ${ }^{14}$ "... to get high school binge drinkers to abandon this behavior, health educators should know the psychosocial factors that are associated empirically with transitions in student drinking." In comparison with this earlier study, which was based on data from a single school, our analysis uses all 4 years of the Harvard School of Public Health College Alcohol Survey, a nationally representative data source, and we expand our analysis to include non-binge drinkers, thereby allowing us to study reductions in alcohol consumption by all drinkers.

\section{Methods}

The data for this study come from the 1993, 1997, 1999, and 2001 rounds of the Harvard School of Public Health's College Alcohol Survey. ${ }^{6,16-18}$ Each year, surveys were sent to random samples of students at up to 140 universities and colleges in the US. Over the 4 years, the number of schools varied from 140 in 1993 to 116 in 1997. In both 1999 and 2001, 119 schools participated in the survey. Response rates were approximately 70 percent in 1993, 59 percent in 1997, 59 percent in 1999, and 52 percent in 2001, ${ }^{6}$ and the resulting sample sizes were 15,282, 14,428, 13,954, and 10,904 in those years, respectively. ${ }^{19-22}$ The surveys contain information on student life, beliefs about alcohol policies, own alcohol consumption, use of alcohol by other students, other personal behaviors, student activities, and background information.

\section{Measures of alcohol consumption}

Respondents were asked two questions about their alcohol consumption during senior year of high school. The first question asked how many times a month the student usually consumed alcohol, and the second asked the number of drinks usually consumed. We consider students who report never drinking when answering both questions to be "nondrinkers" during high school. Female students who usually consumed four or more drinks and male students who usually consumed five or more drinks are considered high school binge drinkers. Although binge drinking typically refers to occasional rather than usual behavior, we call high school students who usually consume four or five drinks binge drinkers for consistency with the description of college drinkers. Those who drank but did not usually binge drink are considered high school non-binge drinkers.

Additionally, a number of questions were asked about alcohol consumption during college. Students were asked how many times they consumed exactly four drinks or five or more drinks within the past 2 weeks. Women who had consumed four or more drinks and men who had consumed five or more drinks are classified as binge drinkers during freshman year. Students who did not binge drink but who had reported consuming alcohol within the past 30 days are classified as freshman non-binge drinkers, and students who had not consumed alcohol within the past 30 days are classified as freshman non-drinkers. Questions about non-binge drinking were asked, with recall periods of 1 week and 30 days, and most of the literature uses recall periods of either 2 weeks ${ }^{6,8,13,16-18}$ or the past 30 days, ${ }^{12,15}$ so we chose to measure non-binge drinking over 30 days rather than 1 week.

Given these definitions, a reduction in drinking can happen in one of three ways. First, a student who drinks but does not usually binge drink in high school can stop drinking. Second, a student who binges in high school can stop drinking. Third, a student who usually binge drank 
during senior year can cut back to non-binge drinking. We do not distinguish among these different changes. Across all 4 survey years, we find that 11.3 percent of all students (including those who do not drink) reduced drinking between senior year of high school and freshman year of college, and that 21.6 percent of high school binge drinkers reduced their consumption during freshman year. These figures are similar to, but smaller than, those reported by Reifman and Watson. ${ }^{14}$

\section{Explanatory variables}

In the existing literature, explanatory variables are typically grouped into a number of categories where the specific categories depend on the question of interest. Because we are exploring a number of different possible relationships, we use variables from a number of different categories: demographic and parental background characteristics, ${ }^{7,14,15,23}$ other substance abuse, ${ }^{9}$ the consequences of other students' alcohol use, ${ }^{6,16-18}$ the social environment (including living arrangements), ${ }^{8,14,23-25}$ student activities, ${ }^{14}$ and attitudes toward alcohol policy and exposure to alcohol education. ${ }^{8,13}$

Background variables include indicators for male; race/ ethnicity (non-Hispanic white, non-Hispanic black, nonHispanic Asian, non-Hispanic other race, and Hispanic); religion (catholic, protestant, other religion, and not religious); whether the student reported that the student's mother or father was not a drinker or was a light, moderate, or heavy drinker; whether the student's family approved of alcohol use; and whether the student's mother or father had a high school education or less.

Although students were asked to provide only one race, a handful of individuals provided more than one answer. Because there were not enough of these individuals to include a separate category for multiple race, race for these individuals is coded as the category having the least representation in the data. In the analysis below, female is the omitted category for sex, non-Hispanic white for race/ethnicity, not religious for religion, and mother and father not drinking for the parental drinking variables.

To allow for the fact that some substances may be complements, we next considered the use of cannabis, cigarettes, and powder cocaine. For each of these substances, two variables were created. The first indicates that the student has never used that substance, and the second that the student has used it within the past 30 days. Thus, for each substance, the base group is students who have used the substance at some point in their lives but not in the past 30 days. Additionally, to capture the possibility that negative consequences of others' behavior may affect reductions, we include an indicator of whether the drinking of others led to the student being pushed, hit, or assaulted, and an indicator of whether the drinking of others resulted in an argument.

Social variables include the number of good friends a student reports having (categorized as zero to two, three or four, and five or more), whether the student reports knowing a faculty member or administrator to whom he or she could talk about problems, membership in a fraternity or sorority, and living in a coed dorm, other on-campus housing, off campus but not with parents/other relatives, and off campus with parents/other relatives. Other social variables include indicators equal to one if participation in parties or fraternity/ sorority life is very important or important to the student, an indicator equal to one if the student has had multiple sexual partners in the past 30 days, and the average number of hours per day spent on social activities.

A number of variables measure participation in, and attitudes toward, student activities. These include the average hours per day studying, working for pay, watching television, working with organizations, engaging in physical activity, and volunteer activities. Each of the time use variables is coded as $0,1,2,3,4$, and 5 (=5 or more) hours. Also included are indicators for whether it is important or very important for the student to participate in academic work, religious activities, the arts, or political activities.

The last group of variables measures whether the student believes that the legal drinking age should be less than 21 years, his or her exposure to a number of alcohol education messages, and the avenues through which the alcohol education was received. The alcohol education messages include information about where to obtain help with alcohol problems, the long-term effects of alcohol use, the dangers of alcohol use, and how to recognize problems with alcohol. The ways in which the messages were received include attending lectures, meetings, or workshops; mailings or handouts; posters or signs; announcements or articles in student newspapers; or through a special course on alcohol and other student life issues.

\section{Statistical methods}

Sampling weights are available in the College Alcohol Survey, and all analyses use these weights. The statistical analysis was conducted using Stata 11.2 (StataCorp LP, College Station, TX, USA) using the svy suite of commands to accommodate the nonrandom sampling.

Two approaches were used to analyze the data. The first is a comparison of proportions (except for a few variables 
measuring time spent in various activities, which are measured in hours) for students who do and who do not reduce their alcohol consumption using the "svy: mean" command in Stata. For each variable included in the analysis, we tested the hypothesis that the average for the group that reduces consumption is equal to the average for the group that does not reduce consumption, and we report the $P$-value for each hypothesis test. Hypothesis testing is conducted using the "test" command in Stata. The results of this analysis are reported in Table 1.

Testing for differences in proportions ignores the fact that many of these characteristics are related to each other, and we use a logistic regression model to allow for multiple variables to jointly affect the decision to reduce drinking or not. The explanatory variables are entered in groups. As described previously, the groups of variables (background characteristics, other substance use, the consequences of others' alcohol use, social environment, student activities, and policies) are motivated by the previous literature. The order of inclusion moves broadly from more personal variables (eg, background and substance use) to variables that measure university activities (eg, policy variables). Logistic regression models are estimated using the "svy: logit" command.

The results of logistic regressions are reported as odds ratios (ORs). An OR greater than 1 indicates that an increase in the characteristic is associated with an increase in the odds of cutting back on alcohol, whereas an OR less than 1 indicates that an increase in the characteristic is associated with a decrease in the odds of reducing alcohol consumption. In addition to the OR, the tables include 95 percent confidence intervals for each OR, and the $P$-value for the hypothesis test that the OR is equal to 1 .

The results are reported in Tables $2-6$. Table 2 reports the results of a model that includes only background variables, and Tables 3 through 6 each add one group of variables in turn. Each model includes all of the variables included in the previous models, but, to conserve space, the tables report only the OR for the newly added variables. To assess whether the groups of previous variables remain statistically relevant, each table includes an $F$-statistic for each previously added group of variables. The null hypothesis is that the OR for each variable in the group under test is jointly equal to 1 .

\section{Descriptive statistics}

We limited our analysis sample to students who are 18 or 19 years old, unmarried, and not missing data on key variables. Because we wished to understand reductions in alcohol consumption between high school and college, the analysis sample was also limited to students who reported drinking alcohol during their senior year of high school. The resulting sample contains 5,106 students. Of these, almost 22 percent $(n=1,101)$ reduced their alcohol consumption as previously defined. The remaining 78 percent of students $(n=4,005)$ either continued to drink at their previous level (eg, was a non-binge drinker in both high school and college) or increased their consumption in college (eg, was a non-binge drinker in high school and a binge drinker in college). Table 1 provides descriptive statistics for those who reduced their alcohol consumption and those who did not. The two samples differ significantly in almost all characteristics considered. For example, students who reduced consumption were more likely to be female, less likely to be white, more likely to have parents who did not approve of drinking, and more likely to abstain from other substance use.

\section{Results from adjusted logistic regression models \\ Demographic and parental variables}

Table 2 presents the results of the adjusted model, which includes the demographic or background variables. The results indicate that being male and catholic or another religion was associated with lower odds of reducing alcohol consumption. Compared with having parents who abstained, students with parents who drank moderately or heavily had lower odds of reducing their alcohol consumption. In contrast, being Asian, Hispanic, or black (relative to non-Hispanic white); having parents who disapprove of alcohol consumption; and having a father who did not attend college were all associated with increased odds of cutting back on alcohol consumption.

\section{Other substance use}

We next added variables describing the student's use of other substances and his or her experience with the consequences of other students' drinking during college. These results are presented in Table 3. Having never smoked marijuana or used cocaine was associated with increased odds of reducing alcohol consumption, whereas having smoked cigarettes or marijuana in the past 30 days decreased the odds. Having been hit or assaulted by, or in an argument with, someone due to their drinking was associated with lower odds of reducing consumption. Although the ORs for the background variables are not displayed, the results for the background variables were generally similar to those in Table 2, and the background variables remained jointly statistically significant, as measured by the $F$-statistic. 
Table I Descriptive results by alcohol consumption status ${ }^{2}$

\begin{tabular}{|c|c|c|c|c|c|}
\hline & \multicolumn{2}{|l|}{ Cut back } & \multicolumn{2}{|c|}{ Did not cut back } & \multirow[t]{2}{*}{$P$-value } \\
\hline & Proportion $^{b}$ & Standard error & Proportion ${ }^{\mathrm{b}}$ & Standard error & \\
\hline \multicolumn{6}{|l|}{ Demographic and parental } \\
\hline Female & 60.3 & 1.7 & 53.2 & 0.9 & 0.000 \\
\hline Male & 39.7 & 0.9 & 46.8 & 1.7 & 0.000 \\
\hline White & 71.0 & 1.6 & 82.2 & 0.7 & 0.000 \\
\hline Asian & 8.3 & 1.0 & 5.0 & 0.5 & 0.002 \\
\hline Hispanic & 8.6 & 1.0 & 6.6 & 0.5 & 0.074 \\
\hline Black & 8.7 & 1.0 & 3.3 & 0.3 & 0.000 \\
\hline Other race & 3.4 & 0.7 & 3.0 & 0.3 & 0.561 \\
\hline Not religious & 14.2 & 1.1 & 12.9 & 0.6 & 0.317 \\
\hline Catholic & 39.2 & 1.6 & 44.8 & 0.8 & 0.002 \\
\hline Protestant & 34.2 & 1.5 & 29.7 & 0.8 & 0.008 \\
\hline Other religion & 12.3 & 1.1 & 12.5 & 0.6 & 0.837 \\
\hline Mom light drinker & 53.1 & 1.6 & 57.5 & 0.8 & 0.012 \\
\hline Mom moderate drinker & 7.6 & 0.9 & 11.4 & 0.5 & 0.000 \\
\hline Mom heavy drinker & 2.3 & 0.4 & 3.3 & 0.3 & 0.049 \\
\hline Dad light drinker & 44.0 & 1.6 & 46.0 & 0.8 & 0.279 \\
\hline Dad moderate drinker & 20.5 & 1.3 & 25.5 & 0.7 & 0.001 \\
\hline Dad heavy drinker & 12.4 & 1.1 & 12.3 & 0.6 & 0.984 \\
\hline Parents did not approve of alcohol & 37.4 & 1.6 & 31.0 & 0.8 & 0.000 \\
\hline Mom no college & 36.6 & 1.5 & 29.1 & 0.8 & 0.010 \\
\hline Dad no college & 33.9 & 1.5 & 23.4 & 0.7 & 0.000 \\
\hline \multicolumn{6}{|c|}{ Other substances and consequences of others' use } \\
\hline Never smoked cigarettes & 42.6 & 1.6 & 29.2 & 0.8 & 0.000 \\
\hline Smoked cigarettes past 30 days & 24.5 & 1.4 & 47.2 & 0.8 & 0.000 \\
\hline Never smoked marijuana & 56.3 & 1.6 & 36.0 & 0.8 & 0.000 \\
\hline Smoked marijuana past 30 days & 12.0 & I.I & 33.5 & 0.8 & 0.000 \\
\hline Never used cocaine (not crack) & 97.9 & 0.4 & 92.6 & 0.5 & 0.000 \\
\hline Used cocaine (not crack) past 30 days & 0.3 & 0.2 & 1.6 & 0.2 & 0.000 \\
\hline Assaulted due to others' drinking & 10.9 & 1.0 & 20.1 & 0.7 & 0.000 \\
\hline Argument due to others' drinking & 20.9 & 1.3 & 37.6 & 0.8 & 0.000 \\
\hline \multicolumn{6}{|l|}{ Social environment } \\
\hline Have fewer than 3 good friends & 23.4 & 1.4 & 13.3 & 0.6 & 0.000 \\
\hline Have 3 or 4 good friends & 32.7 & 1.6 & 26.2 & 0.7 & 0.000 \\
\hline Have 5 or more good friends & 43.7 & 1.6 & 60.2 & 0.8 & 0.000 \\
\hline Know a faculty member could talk to & 53.4 & 1.6 & 51.2 & 0.8 & 0.225 \\
\hline Greek & 5.3 & 0.7 & 18.1 & 0.6 & 0.000 \\
\hline Multiple sexual partners past 30 days & 11.7 & 1.1 & 13.1 & 0.6 & 0.278 \\
\hline Hours of social activities & 2.9 & 0.05 & 3.4 & 0.02 & 0.000 \\
\hline Parties (very) important & 27.0 & 1.5 & 62.5 & 0.8 & 0.000 \\
\hline Fraternity/sorority life (very) important & 7.4 & 0.9 & 20.9 & 0.7 & 0.000 \\
\hline Single sex dorm & 23.7 & 1.4 & 21.2 & 0.7 & 0.099 \\
\hline Coed dorm & 39.4 & 1.6 & 56.8 & 0.8 & 0.000 \\
\hline On campus - other housing & 16.7 & 1.3 & 10.3 & 0.5 & 0.000 \\
\hline Off campus not with parents & 4.8 & 1.2 & 4.3 & 0.5 & 0.589 \\
\hline Off campus with parents & I5. I & 0.8 & 7.4 & 0.3 & 0.000 \\
\hline \multicolumn{6}{|l|}{ Student activities } \\
\hline Academic work (very) important & 97.0 & 0.4 & 97.2 & 0.3 & 0.199 \\
\hline Religious activities (very) important & 43.6 & 1.6 & 34.4 & 0.8 & 0.000 \\
\hline Arts (very) important & 21.4 & 1.3 & 22.2 & 0.7 & 0.620 \\
\hline Political activism (very) important & 16.1 & 1.2 & 16.0 & 0.6 & 0.943 \\
\hline Community service (very) important & 38.8 & 1.6 & 33.3 & 0.8 & 0.002 \\
\hline Hours of studying & 2.8 & 0.05 & 2.7 & 0.02 & 0.286 \\
\hline Hours of work & 2.1 & 0.07 & $\mathrm{I} .4$ & 0.03 & 0.000 \\
\hline Hours of television & 2.1 & 0.05 & 2.0 & 0.03 & 0.033 \\
\hline Hours of working with organizations & 0.6 & 0.03 & 0.7 & 0.02 & 0.000 \\
\hline Hours of physical activity & 1.1 & 0.04 & 1.3 & 0.02 & 0.000 \\
\hline Hours of volunteer work & 0.3 & 0.03 & 0.3 & 0.01 & 0.156 \\
\hline
\end{tabular}


Table I (Continued)

\begin{tabular}{|c|c|c|c|c|c|}
\hline & \multicolumn{2}{|l|}{ Cut back } & \multicolumn{2}{|c|}{ Did not cut back } & \multirow[t]{2}{*}{$P$-value } \\
\hline & Proportion $^{b}$ & Standard error & Proportion ${ }^{b}$ & Standard error & \\
\hline \multicolumn{6}{|l|}{ Policies } \\
\hline Believe legal drinking age should be $<2$ I years & 85.3 & 1.5 & 66.5 & 0.6 & 0.000 \\
\hline \multicolumn{6}{|l|}{ Have you received information on: } \\
\hline Where to get help with alcohol problems & 65.2 & 1.6 & 72.8 & 0.8 & 0.000 \\
\hline Long-term effects of alcohol & 47.5 & 1.6 & 52.0 & 0.8 & 0.014 \\
\hline Dangers of alcohol & 53.8 & 1.6 & 61.1 & 0.8 & 0.000 \\
\hline How to recognize problems & 45.3 & 1.6 & 52.6 & 0.8 & 0.000 \\
\hline \multicolumn{6}{|l|}{ Have you received information through: } \\
\hline Lectures & 25.6 & 1.5 & 28.3 & 0.8 & 0.105 \\
\hline Mailings & 43.8 & 1.6 & 50.5 & 0.8 & 0.000 \\
\hline Posters & 70.6 & 1.5 & 80.7 & 0.7 & 0.000 \\
\hline Newspapers & 55.6 & 1.6 & 63.0 & 0.8 & 0.000 \\
\hline Classes & 9.4 & 1.0 & 8.8 & 0.5 & 0.612 \\
\hline Number of observations & 1,101 & & 4,005 & & \\
\hline
\end{tabular}

Notes: 'Authors' calculations from the 1993, 1997, 1999, and 2001 Harvard School of Public Health College Alcohol Study. Observations are weighted by the sampling weights provided in the surveys. "P-value" is the $P$-value for a hypothesis test that the average for students to reduce consumption is equal to the average for students who do not reduce consumption; bAll variables are proportions except for those that measure time spent on various activities, which are measured in hours.

\section{Social environment}

The next specification adds variables describing the student's social environment, and results of this specification are reported in Table 4. We find that living in a coed dorm (relative to a single sex dorm) lowered the odds of drinking less, whereas living off campus increased the odds. The odds

Table 2 Adjusted logistic regression of reduced alcohol consumption: background variables ${ }^{a}$

\begin{tabular}{llll}
\hline Variable & $\begin{array}{l}\text { Adjusted } \\
\text { odds ratio }\end{array}$ & $\begin{array}{l}\text { 95\% confidence } \\
\text { interval }\end{array}$ & P-value \\
\hline Male & 0.730 & $0.624-0.852$ & 0.000 \\
Asian & 1.800 & $1.288-2.516$ & 0.001 \\
Hispanic & 1.517 & $1.110-2.073$ & 0.009 \\
Non-Hispanic black & 2.777 & $1.974-3.907$ & 0.000 \\
Non-Hispanic other race & 1.244 & $0.780-1.983$ & 0.359 \\
Catholic & 0.769 & $0.604-0.978$ & 0.032 \\
Protestant & 0.963 & $0.754-1.231$ & 0.766 \\
Other religion & 0.743 & $0.548-1.006$ & 0.055 \\
Mom light drinker & 0.847 & $0.707-1.014$ & 0.071 \\
Mom moderate drinker & 0.643 & $0.474-0.873$ & 0.005 \\
Mom heavy drinker & 0.619 & $0.389-0.984$ & 0.042 \\
Dad light drinker & 0.854 & $0.690-1.058$ & 0.148 \\
Dad moderate drinker & 0.741 & $0.577-0.952$ & 0.019 \\
Dad heavy drinker & 0.762 & $0.577-1.007$ & 0.056 \\
Parents do not approve & 1.164 & $0.990-1.367$ & 0.066 \\
of alcohol & & & \\
Mom no college & 1.056 & $0.893-1.247$ & 0.525 \\
Dad no college & 1.551 & $1.305-1.843$ & 0.000 \\
F-statistic - background & 7.09 & & 0.000 \\
variables & & & \\
\hline Note Depr & &
\end{tabular}

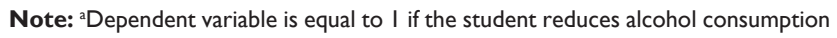
and 0 otherwise. $n=5,106$. Sampling weights are used in the analysis. The base categories for the discrete variables are female, white non-Hispanic, not religious, mom does not drink, dad does not drink, parents approved of at least some alcohol use, mom at least attended college, and dad at least attended college. The model also includes year indicators for 1997, 1999, and 2001. of reducing alcohol consumption were significantly lower for students for whom it was important or very important to participate in fraternity or sorority life, for students for whom it was important or very important to participate in parties, for students who were members of fraternities or sororities, for students with five or more good friends, and for students who spent more time on social activities. The ORs

Table 3 Adjusted logistic regression of reduced alcohol consumption: other substances and consequences of others' alcohol use ${ }^{\mathrm{a}}$

\begin{tabular}{|c|c|c|c|}
\hline Variable & $\begin{array}{l}\text { Adjusted } \\
\text { odds ratio }\end{array}$ & $\begin{array}{l}95 \% \text { confidence } \\
\text { interval }\end{array}$ & $P$-value \\
\hline Never smoked cigarettes & 0.923 & $0.764-1.115$ & 0.405 \\
\hline $\begin{array}{l}\text { Smoked cigarettes } \\
\text { past } 30 \text { days }\end{array}$ & 0.485 & $0.397-0.593$ & 0.000 \\
\hline Never smoked marijuana & 1.219 & $1.018-1.461$ & 0.032 \\
\hline $\begin{array}{l}\text { Smoked marijuana } \\
\text { past } 30 \text { days }\end{array}$ & 0.450 & $0.353-0.572$ & 0.000 \\
\hline $\begin{array}{l}\text { Never used cocaine } \\
\text { (not crack) }\end{array}$ & 1.676 & $1.005-2.796$ & 0.048 \\
\hline $\begin{array}{l}\text { Used cocaine (not crack) } \\
\text { past } 30 \text { days }\end{array}$ & 0.723 & $0.192-2.729$ & 0.632 \\
\hline $\begin{array}{l}\text { Assaulted due to others' } \\
\text { drinking }\end{array}$ & 0.763 & $0.60 \mathrm{I}-0.968$ & 0.026 \\
\hline $\begin{array}{l}\text { Argument due to others' } \\
\text { drinking }\end{array}$ & 0.572 & $0.475-0.689$ & 0.000 \\
\hline $\begin{array}{l}\text { F-statistic - substance } \\
\text { use variables }\end{array}$ & 63.74 & & 0.000 \\
\hline $\begin{array}{l}F \text {-statistic - background } \\
\text { variables }\end{array}$ & 5.93 & & 0.000 \\
\hline
\end{tabular}

Note: ${ }^{\mathrm{D}} \mathrm{Dependent}$ variable is equal to $I$ if the student reduces alcohol consumption and 0 otherwise. $n=5,106$. Sampling weights are used in the analysis. All variables from Table 2 are included. The base categories for the discrete variables are smoked cigarettes but not in past 30 days, smoked marijuana but not in past 30 days, used cocaine but not in past 30 days, was not assaulted due to others' drinking, and was not in an argument due to others' drinking. 
Table 4 Adjusted logistic regression of reduced alcohol consumption: social environment ${ }^{\mathrm{a}}$

\begin{tabular}{|c|c|c|c|}
\hline Variable & $\begin{array}{l}\text { Adjusted } \\
\text { odds ratio }\end{array}$ & $\begin{array}{l}95 \% \text { confidence } \\
\text { interval }\end{array}$ & $P$-value \\
\hline Have 3 or 4 good friends & 0.893 & $0.703-1.135$ & 0.355 \\
\hline $\begin{array}{l}\text { Have } 5 \text { or more good } \\
\text { friends }\end{array}$ & 0.658 & $0.525-0.824$ & 0.000 \\
\hline $\begin{array}{l}\text { Know a faculty member } \\
\text { could talk to }\end{array}$ & 1.164 & $0.985-1.375$ & 0.075 \\
\hline $\begin{array}{l}\text { Member of fraternity } \\
\text { or sorority }\end{array}$ & 0.462 & $0.297-0.718$ & 0.001 \\
\hline $\begin{array}{l}\text { Multiple sexual partners } \\
\text { past } 30 \text { days }\end{array}$ & 1.011 & $0.772-1.325$ & 0.935 \\
\hline Hours of social activities & 0.656 & $0.834-0.937$ & 0.000 \\
\hline Parties (very) important & 0.331 & $0.278-0.394$ & 0.000 \\
\hline $\begin{array}{l}\text { Fraternity/sorority life } \\
\text { (very) important }\end{array}$ & 0.696 & $0.463-1.045$ & $0.08 I$ \\
\hline Coed dorm & 0.656 & $0.535-0.804$ & 0.000 \\
\hline On campus - other housing & 0.971 & $0.623-1.514$ & 0.897 \\
\hline Off campus not with parents & 1.319 & $0.968-1.798$ & 0.080 \\
\hline Off campus with parents & 1.288 & $0.968-1.713$ & 0.082 \\
\hline F-statistic - social variables & 75.31 & & 0.000 \\
\hline $\begin{array}{l}\text { F-statistic - substance } \\
\text { use variables }\end{array}$ & 34.86 & & 0.000 \\
\hline $\begin{array}{l}\text { F-statistic - background } \\
\text { variables }\end{array}$ & 4.02 & & 0.000 \\
\hline
\end{tabular}

Note: a Dependent variable is equal to I if the student reduces alcohol consumption and 0 otherwise. $n=5,106$. Sampling weights are used in the analysis. All variables from Tables 2 and 3 are included. The base categories for the discrete variables are have no to two good friends, do not know a faculty member could talk to about problems, not a member of fraternity or sorority, did not have multiple sexual partners in past 30 days, parties not important, fraternity or sorority life not important, and single sex dorm.

for the background and substance use variables were largely unchanged, and the $F$-statistics showed that these variables remained jointly statistically significant.

\section{Student activity variables}

Table 5 reports the results of the next specification that adds variables describing the student's interest in, and time spent on, a number of activities. Relatively few of the student activities variables were statistically associated with reductions in drinking. Believing that participating in community service activities is important or very important was associated with an increase in the likelihood of drinking less, as was time spent working and watching television. The effects of the previously considered variables were largely unchanged.

\section{Policy variables}

Finally, Table 6 adds variables describing alcohol education policies the student has been exposed to, the setting in which the student has been exposed to these messages, and the student's belief about whether the legal drinking age should be less than 21 years. Students who believed that the drinking age should be less than 21 years were significantly less likely
Table 5 Adjusted logistic regression of reduced alcohol consumption: student activities ${ }^{\mathrm{a}}$

\begin{tabular}{|c|c|c|c|}
\hline Variable & $\begin{array}{l}\text { Adjusted } \\
\text { odds ratio }\end{array}$ & $\begin{array}{l}95 \% \text { confidence } \\
\text { interval }\end{array}$ & $P$-value \\
\hline $\begin{array}{l}\text { Academic work (very) } \\
\text { important }\end{array}$ & 1.339 & $0.7 \mid 4-2.513$ & 0.363 \\
\hline $\begin{array}{l}\text { Religious activities (very) } \\
\text { important }\end{array}$ & 1.123 & $0.937-1.346$ & 0.209 \\
\hline Arts (very) important & 1.179 & $0.962-1.446$ & 0.113 \\
\hline $\begin{array}{l}\text { Political activism (very) } \\
\text { important }\end{array}$ & 1.045 & $0.827-1.321$ & 0.710 \\
\hline $\begin{array}{l}\text { Community service (very) } \\
\text { important }\end{array}$ & 1.281 & $1.058-1.552$ & 0.011 \\
\hline Hours of studying & 0.987 & $0.925-1.053$ & 0.686 \\
\hline Hours of work & 1.058 & $1.012-1.107$ & 0.013 \\
\hline Hours of television & $\mathrm{I} .054$ & $0.992-1.121$ & 0.091 \\
\hline $\begin{array}{l}\text { Hours of working } \\
\text { with organizations }\end{array}$ & 0.932 & $0.85 \mathrm{I}-1.020$ & 0.124 \\
\hline Hours of physical activity & 0.968 & $0.895-1.048$ & 0.424 \\
\hline Hours of volunteer work & 1.073 & $0.962-1.197$ & 0.204 \\
\hline $\begin{array}{l}\text { F-statistic }- \text { student } \\
\text { activity variables }\end{array}$ & 1.90 & & 0.034 \\
\hline $\begin{array}{l}\text { F-statistic - social } \\
\text { variables }\end{array}$ & 70.19 & & 0.000 \\
\hline $\begin{array}{l}\text { F-statistic - substance } \\
\text { use variables }\end{array}$ & 33.10 & & 0.000 \\
\hline $\begin{array}{l}F \text {-statistic - background } \\
\text { variables }\end{array}$ & 3.69 & & 0.000 \\
\hline
\end{tabular}

Note: aDependent variable is equal to $I$ if the student reduces alcohol consumption and 0 otherwise. $n=5,106$. Sampling weights are used in the analysis. All variables from Tables 2,3, and 4 are included. The base categories for the discrete variables are having no to two good friends, do not know a faculty member could talk to about problems, not a member of fraternity or sorority, did not have multiple sexual partners in past 30 days, parties not important, fraternity or sorority life not important, and single sex dorm.

to reduce their alcohol consumption (recall these students are all 18 or 19 years old). The only statistically significant effect of alcohol education was that receiving information through posters on campus reduces the likelihood of drinking less. The $F$-statistics showed that each group of variables remained statistically related to reductions in consumption, even with all other variables included. Although ORs are not reported for all of the variables for each of the models, we note that being male, having a mother who was a moderate drinker, having a mother who was a heavy drinker, never having smoked marijuana, and living off campus were no longer statistically related to reducing alcohol consumption in the full specification, even though they were in earlier specifications.

\section{Predicted probabilities}

Estimates from the logistic regressions can be used to construct predicted probabilities for different combinations of explanatory variables. As an alternative way to characterize some of the results, we construct predicted probabilities for 
Table 6 Adjusted logistic regression of reduced alcohol consumption: policies - policy variables ${ }^{\mathrm{a}}$

\begin{tabular}{|c|c|c|c|}
\hline Variable & $\begin{array}{l}\text { Adjusted } \\
\text { odds ratio }\end{array}$ & $\begin{array}{l}95 \% \text { confidence } \\
\text { interval }\end{array}$ & $P$-value \\
\hline \multicolumn{4}{|l|}{ Policies } \\
\hline $\begin{array}{l}\text { Believe legal drinking age } \\
\text { should be }<21 \text { years }\end{array}$ & 0.506 & $0.419-0.612$ & 0.000 \\
\hline $\begin{array}{l}\text { Have you received } \\
\text { information on: }\end{array}$ & & & \\
\hline $\begin{array}{l}\text { Where to get help } \\
\text { with alcohol problems }\end{array}$ & 0.903 & $0.728-|| 2 \mid$. & 0.356 \\
\hline $\begin{array}{l}\text { Long-term effects } \\
\text { of alcohol }\end{array}$ & 1.089 & $0.847-1.40 \mid$ & 0.507 \\
\hline Dangers of alcohol & 0.945 & $0.722-1.239$ & 0.684 \\
\hline \multicolumn{4}{|l|}{$\begin{array}{l}\text { Have you received } \\
\text { information through: }\end{array}$} \\
\hline Lectures & 1.039 & $0.845-1.277$ & 0.717 \\
\hline Mailings & 1.021 & $0.845-1.234$ & 0.828 \\
\hline Posters & 0.758 & $0.6 \mid 3-0.937$ & 0.010 \\
\hline Newspapers & 0.880 & $0.733-1.056$ & 0.169 \\
\hline Classes & 1.285 & $0.95 \mathrm{I}-1.735$ & 0.103 \\
\hline F-statistic - policy variables & 13.38 & & 0.000 \\
\hline $\begin{array}{l}F \text {-statistic }- \text { student } \\
\text { activity variables }\end{array}$ & 1.89 & & 0.036 \\
\hline F-statistic - social variables & 55.27 & & 0.000 \\
\hline $\begin{array}{l}\text { F-statistic - substance } \\
\text { use variables }\end{array}$ & 30.56 & & 0.000 \\
\hline $\begin{array}{l}F \text {-statistic - background } \\
\text { variables }\end{array}$ & 3.32 & & 0.000 \\
\hline
\end{tabular}

Note: aDependent variable is equal to $I$ if the student reduces alcohol consumption and 0 otherwise. $n=5,106$. Sampling weights are used in the analysis. All variables from Tables 2, 3, 4, and 5 are included. The base categories for the discrete variables are: believe the legal drinking age should be at least 21 years; have not received information on where to get help with problems, long-term effects of problems, the dangers of alcohol, or how to recognize problems; and have not received information through lectures, mailings, posters, newspapers, or classes.

a number of different combinations of background characteristics and social variables. We first vary the parental drinking variables and separately vary father's education while leaving all other variables unchanged, and present these results in Figure 1. The first three bars show the average probabilities of reducing alcohol consumption under the assumptions that each student's parents abstained, the student's father was a heavy drinker and mother did not drink, and both parents were heavy drinkers, respectively. Compared with living in a family where both parents abstain, living in a family where both parents are heavy drinkers was associated with less than a 10 percentage point reduction in the probability of cutting back on alcohol consumption. However, the average predicted probabilities were not statistically different from each other, as measured by the $95 \%$ confidence intervals represented by the "error bands" in the figure.

The remaining two bars show the probabilities assuming first that all students have a father who did not attend college and then assuming that all fathers had at least some college education. In this case, the estimated probability of reducing alcohol fell by about 4 percentage points for students whose fathers had more than a high school education.

To better understand the magnitude of some of the key social variables, Figure 2 repeats this exercise except that sex, being a member of a Greek organization (social fraternity or sorority), believing that participating in Greek life was important or very important, and believing that participating in parties was important or very important were the characteristics that were varied. The highest probability of reducing consumption is for women who were not associated with the Greek system ("Greek" in this case means both membership and believing that participation in Greek life is important) and who did not believe that participation in parties is important. As we compare the four male-female pairs, we see the small estimated effect of being male. In this case, the largest effect was for the Greek system, though that does involve changing two variables. Unsurprisingly, the most significant reduction

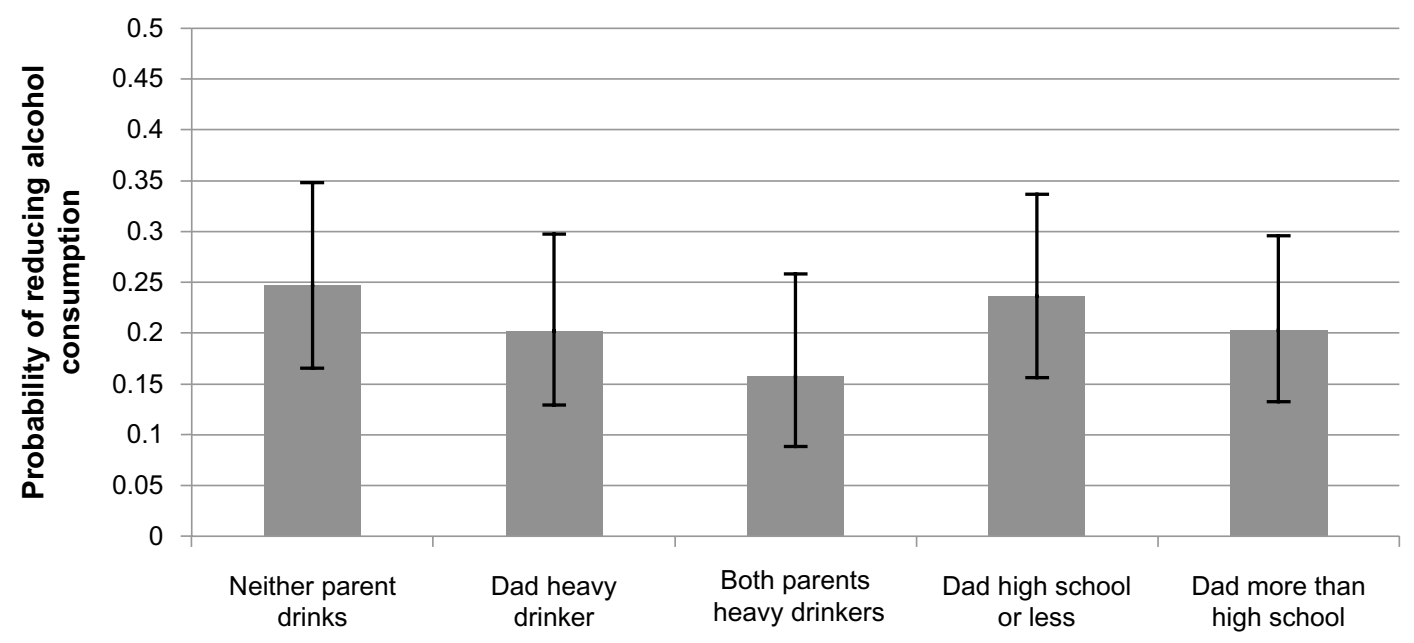

Figure I Estimated effects of parental characteristics. 


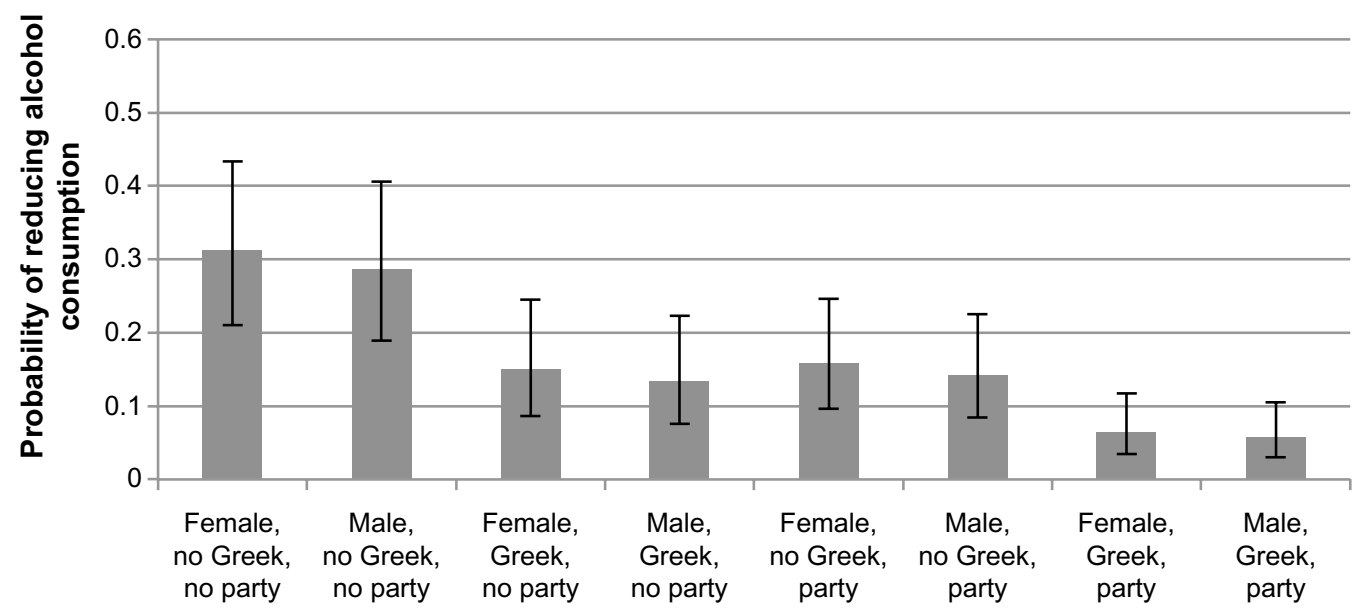

Figure 2 Estimated effects of sex, Greek affiliation, and the importance of parties.

Notes: Greek indicates membership in a social fraternity or sorority and belief that participation in Greek life is important or very important. Party indicates the belief that participation in parties is important or very important.

occurs for students who were members of the Greek system and who believed that participating in that system and in parties was important or very important.

\section{Discussion}

A number of background characteristics emerge from the analysis as being strongly and consistently related to reductions in alcohol consumption. Across all models, we found that the odds of reducing alcohol consumption were significantly higher for Asian and African-American students and for students whose fathers did not attend college. The odds of reducing alcohol consumption were significantly lower for students whose fathers were moderate or heavy drinkers, and there is some evidence that it was lower for students whose mothers were moderate drinkers. Additionally, we found some evidence that male students have lower odds of reducing alcohol consumption. Because being male is frequently found to be a risk factor for increases in drinking, ${ }^{26}$ it is notable that the effect of being male weakened in magnitude and statistical significance as other predictors were added to the model, and became statistically insignificant at conventional levels in the final specification (not reported in Table 6 , $\mathrm{OR}=0.863$; confidence interval $=0.719-1.035$ ).

Our finding that the odds of reducing alcohol consumption were significantly higher for students whose father did not attend college is notable and might reflect a number of things. First, because we do not control for family income, this result may capture an inverse relationship between family income and the probability of reducing alcohol consumption. Second, our finding may reflect differences in attitudes and expectations about the college experience for those students whose fathers did not attend college versus those whose fathers did. It is worth further investigating why this is the case, because this finding persisted even after controlling for many other characteristics.

Our results further suggest that recent use of cigarettes and marijuana lowered the odds of reducing alcohol consumption, whereas recent use of cocaine was not associated with reductions. At the same time, students who had never used cocaine were significantly more likely to reduce their alcohol consumption. These results suggest that using cocaine was different from using the other substances and that drinking alcohol and smoking either tobacco or marijuana tended to occur together. Although we are unable to disentangle the timing of exposure to different substances, there is evidence that exposure to alcohol is almost universal by college (with tobacco and marijuana not far behind), whereas exposure to cocaine is much lower. ${ }^{9}$ Interestingly, negative consequences of others' drinking appeared to reduce the likelihood of curtailing alcohol consumption. This result likely reflects a reverse causality where heavy drinkers were exposed to more arguments and other negative consequences.

Consistent with the previous literature, we find that the social environment matters a great deal for drinking behavior. The variable with the largest effect on maintaining or increasing drinking levels from high school was having the attitude that it is important or very important to participate in parties during college. Also significant were membership in a Greek organization, believing that participating in fraternity and sorority life was important or very important, having five or more good friends, living in a coed dorm, and spending more time in social activities. These results were robust to the inclusion or exclusion of additional control variables.

In contrast to the relationship between drinking and attitudes toward parties and Greek life, there was little relationship between student priorities and activities and reductions 
in drinking. Only the relationship between drinking and community service achieved statistical significance. It is perhaps not surprising to find that working more was associated with a reduction in drinking, but it is also the case that spending more time watching television was associated with a reduction in drinking.

The strong finding that students who believed that the legal drinking age should be less than 21 years old were less likely to reduce their alcohol consumption is consistent with the literature and reinforces the theory of social norms where the students believe that the normative behavior should be the same as their behavior.

\section{Limitations}

It is important to keep in mind a number of limitations of our analysis. First, although we used 4 years of data, our analysis was fundamentally cross-sectional with retrospective reporting of high school alcohol use. To the extent that students did not accurately remember their consumption of alcohol or chose to misrepresent it, the analysis will be biased. Second, the measures of alcohol used and the time frames covered varied between high school and college and for binge and non-binge drinking in college. High school drinking was constructed from questions asking about usual drinking behavior during senior year of high school, whereas college drinking behavior was assessed more precisely over the previous 2 weeks or 30 days. Students categorized as binge drinkers in high school were those who reported usually binge drinking, and there may have been students who occasionally binge drank in high school who were not counted as binge drinkers. However, measurement error in classifying the level of drinking was somewhat moderated because we were looking at reductions in drinking. Thus, a student who was an occasional but not usual binge drinker was still included in the analysis. Third, as noted earlier, we grouped together students who were high school binge drinkers and college non-binge drinkers, students who were high school binge drinkers and college abstainers, and students who were high school non-binge drinkers and college abstainers. To the extent that different characteristics affected those groups differently, those distinctions were lost in this analysis. Fourth, because we used cross-sectional data without randomization over any of the explanatory variables such as alcohol policies and membership in Greek organizations, we were unable to uncover causal relationships. Finally, given the exploratory nature of our secondary data analysis, we could not conduct a priori power analyses, so it is possible that some of our results are underpowered.

\section{Conclusion}

High rates of alcohol consumption have been shown to have significant consequences for college students, including assaults and deaths. Consequently, a significant amount of research has investigated the individual, family, and school characteristics that are associated with increases in drinking before and during college. A smaller number of studies examined the factors associated with decreases in consumption during college. We explore the characteristics and behaviors associated with reductions in alcohol consumption between high school and college.

Our analysis uses data from the 1993, 1997, 1999, and 2001 rounds of the Harvard School of Public Health College Alcohol Survey. Twenty-two percent of the sample reduced their consumption of alcohol between high school and college. We group the explanatory variables as demographic and parental background characteristics, other substance use, social environment, student activities, and alcohol education experience. Using logistic regression models, we find that a number of characteristics, including race, father's education, smoking tobacco and marijuana, the social environment, and attitudes toward alcohol policy, affect reductions in drinking.

\section{Acknowledgments}

We would like to thank Jeremy Bray for helpful comments on an earlier version of this paper.

\section{Disclosure}

The authors report no conflicts of interest in this work.

\section{References}

1. Testa M, Hoffman JH. Naturally occurring changes in women's drinking from high school to college and implications for sexual victimization. J Stud Alcohol Drugs. 2012;73:26-33.

2. Mohler-Kuo M, Dowdall GW, Koss MP, Wechsler H. Correlates of rape while intoxicated in a national sample of college women. J Stud Alcohol. 2004;65:37-45.

3. Nelson TF, Xuan Z, Lee H, Weitzman ER, Wechsler H. Persistence of heavy drinking and ensuing consequences at heavy drinking colleges. J Stud Alcohol Drugs. 2009;70:726-734.

4. Testa M, Livingston JA. Alcohol consumption and women's vulnerability to sexual victimization: can reducing women's drinking prevent rape? Subst Use Misuse. 2009;44:1349-1376.

5. Hingson R, Zha W, Weitzman E. Magnitude of and trends in alcoholrelated mortality and morbidity among U.S. college students ages 18-24, 1988-2005. J Stud Alcohol Drugs. 2009;Suppl 16:12-20.

6. Wechsler H, Lee J, Kuo M, Seibring M, Nelson T, Lee H. Trends in college binge drinking during a period of increased prevention efforts. J Am Coll Health. 2002;50:203-217.

7. Lo C, Globetti C. A partial analysis of the campus influence on drinking behavior: students who enter college as non-drinkers. J Drug Issues. 1993;23:715-725.

8. Weitzman E, Nelson T, Wechsler H. Taking up binge drinking in college: the influences of person, social group, and environment. JAdolesc Health. 2003;32:29-35. 
9. Arria AM, Caldeira KM, O'Grady KE, et al. Drug exposure opportunities and use patterns among college students: results of a longitudinal prospective cohort study. Subst Abuse. 2008;29(4):19-38.

10. Labrie J, Lamb T, Pedersen E. Changes in drinking patterns across the transition to college among first-year college males. J Child Adolesc Subst Abuse. 2009;18:1-15.

11. Weingardt K, Baer J, Kivlahan D, Roberts L, Miller E, Marlatt G Episodic heavy drinking among college students: methodological issues and longitudinal perspectives. Psychol Addict Behav. 1998;12: 155-167.

12. Steinman K. College students' early cessation from episodic heavy drinking: prevalence and correlates. J Am Coll Health. 2003;51: 197-204.

13. Paek H, Hove T. Determinants of underage college student drinking: implications for four major alcohol reduction strategies. $J$ Health Commun. 2012;17:659-676.

14. Reifman A, Watson W. Binge drinking during the first semester of college: continuation and desistance from high school patterns. $J \mathrm{Am}$ Coll Health. 2003;52:73-81.

15. Sher K, Rutledge P. Heavy drinking across the transition to college predicting first-semester heavy drinking from precollege variables. Addict Behav. 2007;32:819-835.

16. Wechsler H, Davenport A, Dowdall G, Moeykens B, Castillo S. Health and behavioral consequences of binge drinking in college: a national survey of students at 140 campuses. JAMA. 1994;272:1672-1677.

17. Wechsler H, Dowdall G, Maenner G, Gledhill-Hoyt J, Lee H. Changes in binge drinking and related problems among American college students between 1993 and 1997. J Am Coll Health. 1998;47:57-68.

18. Wechsler H, Lee J, Kuo M, Lee H. College binge drinking in the 1990s: a continuing problem. J Am Coll Health. 2000;48:199-210.
19. Wechsler H. Harvard School of Public Health College Alcohol Study, 1993: codebook. Available from: http://www.icpsr.umich.edu/cgi-bin/ file comp $=$ none $\&$ study $=6577 \& d s=1 \&$ file_id $=739595$. Accessed December 9, 2013.

20. Wechsler H. Harvard School of Public Health College Alcohol Study, 1997: codebook. Available from: http://www.icpsr.umich.edu/cgi-bin/ file comp $=$ none $\&$ study $=3163 \& d s=1 \&$ file_id $=739708$. Accessed December 9, 2013.

21. Wechsler H. Harvard School of Public Health College Alcohol Study, 1999: codebook. Available from: http://www.icpsr.umich.edu/cgibin/file?comp=none\&study=3818\&ds=1\&file_id=739596. Accessed December 9, 2013.

22. Wechsler H. Harvard School of Public Health College Alcohol Study, 2001: codebook. Available from: http://www.icpsr.umich.edu/cgi$\mathrm{bin} /$ file? $\mathrm{comp}=$ none $\&$ study $=4291 \& \mathrm{ds}=1 \&$ file_id $=916023$. Accessed December 9, 2013.

23. Borsari B, Murphy JG, Barnett NP. Predictors of alcohol use during the first year of college: implications for prevention. Addict Behav. 2007;32;2062-2086

24. Harford TC, Wechsler H, Muthen BO. The impact of current residence and high school drinking on alcohol problems among college students. J Stud Alcohol. 2002;63:271-279.

25. Cross JE, Zimmerman D, O'Grady MA. Residence hall room type and alcohol use among college students living on campus. Environ Behav 2009;41(4):583-603.

26. Wechsler H. Alcohol and the American college campus: a report from the Harvard School of Public Health. Change. 1996;28:20-25.
Substance Abuse and Rehabilitation

\section{Publish your work in this journal}

Substance Abuse and Rehabilitation is an international, peer-reviewed, open access journal publishing original research, case reports, editorials, reviews and commentaries on all areas of addiction and substance abuse and options for treatment and rehabilitation. The manuscript management system is completely online and includes a very quick and fair

\section{Dovepress}

peer-review system. Visit http://www.dovepress.com/testimonials.php to read real quotes from published authors. 